\title{
Quantitative Morphology of Endocrine Cells in Human Fetal Pancreas
}

\author{
A. Clark and A. M. Grant \\ Diabetes Research Laboratories, Radcliffe Infirmary and Nuffield Department of Clinical Biochemistry, \\ John Radcliffe Hospital, Headington, Oxford, UK
}

\begin{abstract}
Summary. Sections of pancreas from human fetuses, 6-20 weeks gestation, were stained with immunoperoxidase for insulin (B cells), glucagon (A cells), pancreatic polypeptide or somatostatin ( $\mathrm{D}$ cells). Morphometric analyses were performed on sections from head and tail regions of each fetus. No stained cells were found at 7 weeks. A, B, pancreatic polypeptide and D cells were found at 9 weeks in primitive islets or as isolated cells adjacent to duct cells. There was no relationship between the density of each endocrine cell type and fetal age, but there was a significant increase in the relative density (percentage total endocrine cells) of D cells from 10-20 weeks
\end{abstract}

$(p<0.01)$. The tail contained significantly more A cells $(p<$ $0.05)$ and less pancreatic polypeptide cells $(p<0.01)$ than the head but similar densities of B and D cells. Lobules containing a high density of pancreatic polypeptide cells and few A cells were found in the posterior part of the head in six fetuses, aged 10-20 weeks.

Key words. Morphometry, endocrine cells, human fetal pancreas, immunocytochemistry, pancreatic polypeptide-rich lobules.
Pancreatic endocrine tissue appears early in fetal development and is present at 10 weeks gestation in man [1,2] and at 12 days gestation in the rat [3]. Endocrine cells arise adjacent to dividing duct cells and it is thought that differentiation of the duct epithelial cells gives rise to both exocrine and endocrine components in the rat [3]. The population of endocrine cells in the islet is not uniform throughout the adult pancreas; the high density of pancreatic polypeptide cells in lobules ('PP rich') of the head region may reflect the ontogeny of this part from the ventral primordium [4]. These 'PP rich' lobules have been found in the neonate [5] and in mid-term fetal pancreas [6]. A higher density of somatostatin containing $\mathrm{D}$ cells has been found in the neonatal pancreas [5] than is seen in the adult [7]. Although decreased numbers of $\mathrm{D}$ cells have been implicated in infant nesidioblastosis [8,9], there is no quantitative estimation of the differentiation of these cells during gestation.

This study identifies the earliest appearance during gestation of four types of endocrine cells (A cells containing glucagon, B cells containing insulin, D cells and pancreatic polypeptide cells) in human fetal pancreas by immunocytochemical staining. Changes in the density and relative proportions of these cell types in different regions of the pancreas during development from $10-20$ weeks gestation is estimated by morphometry.

\section{Methods}

Human fetal pancreas was obtained from embryos within $6 \mathrm{~h}$ of prostaglandin-induced delivery for termination of pregnancy or hysterectomy. Fetal age was estimated by crown-rump measurements [10]. Only well preserved tissue was included.

In older fetuses, the pancreas, spleen and duodenum were removed together and fixed in Bouin's solution or $10 \%$ formol saline. Larger specimens of pancreas were divided into two or more blocks from each of head, body and tail regions. To maintain anterior-posterior orientation, specimens were marked with eosin before embedding in wax. Whole body, anterio-posterior sections were cut of the 7-week fetus.

Two sets of four serial sections (section thickness $5 \mu \mathrm{m}$ ) were cut from the blocks at an interval of $100 \mu \mathrm{m}$ and each set was stained using the indirect immunoperoxidase technique [11] with primary antibodies to insulin (B cells) (Miles Diagnostics, Slough, UK) or glucagon (A cells) or pancreatic polypeptide (PP cells) or somatostatin (D cells), and 3,3' diaminobenzidine (Sigma London, Poole, UK) as the peroxidase substrate. Controls for the staining technique were (a) omission of the primary antisera in the staining schedule and (b) preabsorption of antisera with the purified antigens (bovine insulin $1 \mathrm{mU} / \mathrm{ml}$; porcine glucagon $0.01 \mathrm{mg} / \mathrm{ml}$; bovine pancreatic polypeptide $0.03 \mathrm{mg} / \mathrm{ml}$; somatostatin $0.03 \mathrm{mg} / \mathrm{ml}$ ). Both methods resulted in negative staining.

Two different endocrine cells were identified simultaneously on the same tissue sections using immunoperoxidase (brown reaction product) and an alkaline phosphatase conjugated antibody (North East Biochemicals, Uxbridge, UK) with a blue reaction product (Diazo reaction).

The relative distribution of the different types of endocrine cell 
was estimated morphometrically using a Manual Optical Picture Analyser (MOP, Kontron, Messergerate, Munich, FRG). The sections were projected at a magnification of $\times 630$ onto a counting frame $\left(463 \mathrm{~cm}^{2}\right)$ and the number of stained cells per standardized field of view counted for each endocrine cell type, using both sets of serial sections. The total area of pancreas scanned for each cell type ranged from 0.8 to $14.3 \mathrm{~mm}^{2}$. Counting was done on 10 fetal pancreases, gestational age 10-20 weeks. Stained cells were easily recognised for morphometry at these early fetal ages. Pancreases from two 9-week fetuses were considered to be too small for accurate cell counting.

In the early fetus (10 weeks) the exocrine epithelial tissue was very poorly developed and was surrounded by a matrix of undifferentiated mesenchyme. The percentage of the section occupied by mesenchymal tissue differed between specimens. To permit comparison of cell counts at different ages, the mesenchymal area on the sections was counted and the cell densities have been expressed as cells $/ 0.1 \mathrm{~mm}^{2}$ epithelial tissue by subtraction of the mesenchymal area from the total pancreatic area of the section.

Lobules containing many PP cells ('PP-rich') were identified in six fetuses and separate counts in this region of each cell type were made. Sections of the remaining four fetuses showing no obvious 'PP-rich' lobules were counted as a single unit. Data analyses included Student's paired t-test and calculation of Pearson correlation coefficient. Values were considered non-significant when $p>0.05$.

\section{Results}

\section{Histological Appearance of Developing Pancreas}

At 7 weeks the pancreas consisted of unbranched tubules lined with columnar epithelium and surrounded by undifferentiated mesenchyme. Two separate areas of pancreas were identified; one area was connected by a duct to the duodenum and an adjacent area bordered the embryonic stomach. There was no evidence from the histochemical staining for cells containing insulin, glucagon, pancreatic polypeptide or somatostatin.

At 9 weeks the pancreatic ducts were branched forming a primitive lobular pattern lined with columnar epithelium and embedded in loose connective tissue. Isolated endocrine cells were found between the bases (contraluminal borders) of these epithelial cells, and showed positive reactions with all four types of antisera. These cells were found in the pancreatic tissue adjacent to the duodenum (head region) and in the pancreatic tail.

The lobular arrangement of branching ducts was more apparent by 10 weeks. Clusters of duct cells formed primitive acini lined with cuboidal epithelium. The endocrine cells had the characteristic large central nucleus and clear cytoplasm, and were present either in groups adjacent to the primitive duct and acinar cells or singly between the contraluminal and lateral borders of the duct cells.

Groups of acini with associated ducts formed more distinct lobules by 12 weeks' gestation. The area of undifferentiated connective tissue between the ducts was much reduced and primitive islets were found in this region together with a rich supply of capillaries. Many single endocrine cells of all types were present at the base of acinar or ductular cells.

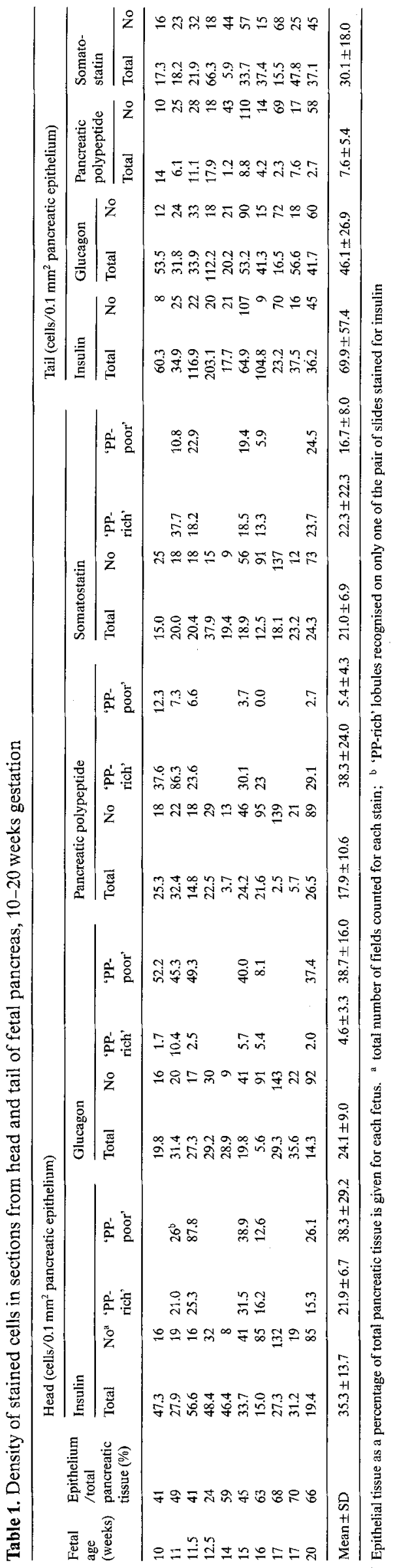




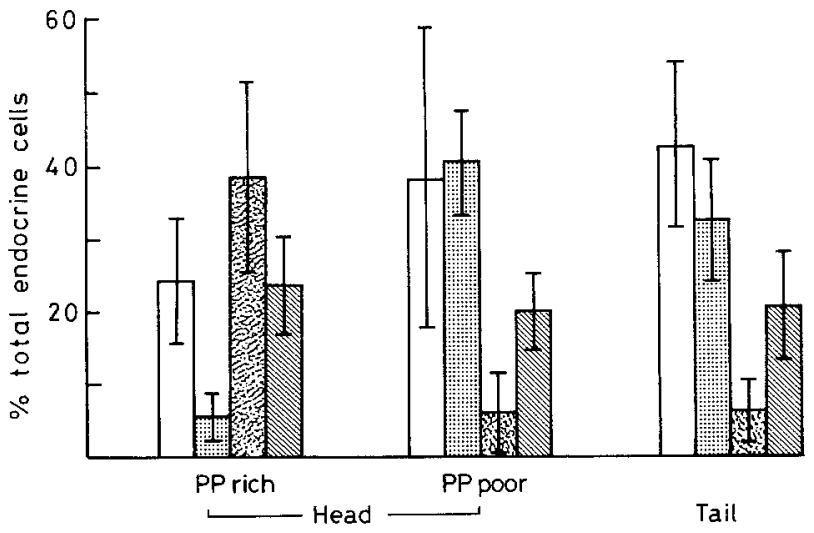

Fig. 1. The distribution of endocrine cells in fetal pancreas $10-20$ weeks gestation. $\square$ B cells, A cells, mis pancreatic polypeptide cells. I) cells. Density of each cell type as a percentage of total endocrine cell density (mean \pm SD) in the tail ( $n=10)$ and 'PP-rich' and 'PP-poor' regions of the head $(n=5)$

The clusters of endocrine cells forming well-defined islets became larger from 14-18 weeks and by 20 weeks the endocrine areas were distinct, lying between the exocrine acinar and duct tissue. Although the majority of the endocrine tissue was found in islets, there were many isolated B, A, PP and D cells adjacent to the duct tissue. Using the double-staining technique, it was apparent that primitive islets consisted of a central core of $B$ cells associated with more peripheral and scattered A, PP and D cells. However, in the 'PP-rich' lobules many islets were composed predominantly of PP cells.

\section{Morphometry}

There was considerable expansion of the exocrine tissue between 10-20 weeks' gestation as shown by the increased percentage of epithelium (Table 1), and the increase in organ weight $(59 \mathrm{mg}$ at 11 weeks to $275 \mathrm{mg}$ at 20 weeks). There was no significant correlation between either the density of each endocrine cell type or all endocrine cells together and the fetal age, 10-20 weeks $(r<0.6$ in all cases); correction for mesenchymal tissue (Table 1) did not reveal a relationship in the head or tail regions. The relative proportions of $\mathrm{B}, \mathrm{A}$ and PP cells (Table 2) did not correlate with fetal age, but there was a significant correlation between the D cells as a percentage of total endocrine cells and fetal age in both the head and tail regions $(r=0.92 ; r=0.85$ respectively; $p<0.01$ ). At 20 weeks in the head and tail regions there were $31 \%$ and $31.5 \% \mathrm{D}$ cells, respectively.

Data from all fetuses (10-20 weeks) were considered together for comparison of cell populations in different regions of the pancreas. There was no significant difference in total endocrine cell density, D cell or B cell density in the two regions. However, there were significantly less A cells $(p<0.05)$ and more PP cells $(p<0.01)$ in the head compared with the tail. The data from the head region were further subdivided into cell counts 
from the 'PP-rich' and 'PP-poor' areas. These lobules could be identified at 11 weeks gestation and were found in the posterior part of the head in six out of ten specimens. The density of PP cells in lobules designated 'PP-rich' was $38.3 \pm 24.0$ cells $/ 0.1 \mathrm{~mm}^{2}$ epithelium (mean \pm SD) which was nine times higher than the density of A cells in that area (Table 1). An inverse relationship of A cells to PP cells was found in the remaining lobules 'PP-poor' (Table 1). There was no significant difference in $\mathrm{B}$ or $\mathrm{D}$ cell densities in the two regions of the head. The data obtained from the 'PP-poor' lobules were similar to those found in the tail (Fig. 1), having a high percentage of A cells and a low percentage of PP cells.

\section{Discussion}

This study shows that all four types of pancreatic endocrine cell can be recognised as early as 9 weeks gestation in the human fetus. By 10 weeks there is clear separation of 'PP-rich' lobules in the pancreatic head, confirming the previous report of Paulin and Dubois [12].

There was no evidence from our study to suggest that the appearance and development of A cells precedes that of other cell types; staining for all cells was negative at 7 weeks and positive at 9 weeks and the cell density of A cells was less than that of B cells at both 10 and 11 weeks. Accurate estimation of the gestational age of a fetus is not always easy, which may be the cause of the variation in observations on the first appearance of endocrine tissue in the pancreas. Only A cells granules were identified in electron microscope sections from a 9 week fetus by Like and Orci [1]. Failure to observe other cell types may have been due to the necessarily small tissue sections sampled for electron microscopy. A cells are also the first endocrine cells to differentiate in fetal rat pancreas [3]. By 10.5 weeks A, B and $D$ cells were identified in human pancreas [1] and $A$ and $D$ cells have also been shown by immunofluorescence at 10-11 weeks' gestation [13]; B cells were not found by these workers until 12 weeks' gestation.

The distribution of PP cells may reflect the ontogeny of the pancreas from two gut diverticulae. MalaisseLagae et al. [4] found that the dorsal region of the pancreatic head, which originates from the ventral primordium, contained many PP cells and few Acells compared with the remainder of the pancreas (dorsal primordial tissue). Similar 'PP-rich' lobules have been identified in rats [14] and dogs [15], and in the human neonate [5]. Although two separate pancreatic buds lying adjacent to the stomach and duodenum were found at 7 weeks' gestation, no endocrine cells were identified until 9 weeks, and no clear pattern of cell distribution was observed at that stage. At 10 weeks 'PP-rich' lobules were identified separated by the pancreatic duct from the 'PP-poor' lobules. The densities of PP and A cells were inversely related in the posterior part of the head
('PP-rich'), and the distribution was reversed in the remainder of the pancreas as seen in the neonate [5]. In contrast to the findings of Rahier et al. [16] no significant regional differences in $\mathrm{D}$ cell density were found.

Factors controlling cellular differentiation may be localised within the developing pancreas since the 'PPrich' lobules can be identified at an early stage of development. All four types of cell are found adjacent to the duct cells on the contraluminal border. Primitive islets then form in the mesenchyme adjacent to the ducts. Endocrine and exocrine cells may arise from a common stem cell and the cytodifferentiation pathway may be determined by both intracellular and extracellular biochemical factors. Infants of diabetic mothers have increased numbers of B cells but also increased densities of A, PP and D cells which implies that a factor, such as hyperglycaemia, can affect the differentiation of all endocrine cell types [17]. Differentiation of both acinar and endocrine tissue in cultured rat embryonic pancreas is unfluenced by glucocorticoids, amino acids, and factors in the mesenchymal tissue [3]. A neural crest origin of 'APUD' (amine precursor uptake decarboxylase) endocrine cells in the rat pancreas [18] is thought to be unlikely, since A and B cells develop after removal of the neural ectoderm from early embryos [3].

The total endocrine density per epithelial area did not change with increased age during a period of rapid pancreatic expansion. This suggests a parallel increase in the growth of endocrine and exocrine tissue from 10-20 weeks. The relative proportions of $B, A$, and PP cells did not alter in the period 10-20 weeks, but there was an increase in the relative density (percentage total endocrine cells) of D cells with age. Somatostatin cells form $30 \%$ endocrine cells in the neonate [5], falling to $20 \%$ in the infant and $8 \%$ in the adult pancreas [16]. A further decrease of D cells with aging has been described [7]. Somatostatin is a powerful inhibitor of the release of endocrine secretions [19]. The high concentration of $\mathrm{D}$ cells in the fetal pancreas may form paracrine inhibitory mechanism for pancreatic and gut hormone secretion which could be partly replaced in the neonate by neurogenic links.

Acknowledgements. We would like to thank Dr. J.W. Keeling and Miss S. Moore for their assistance in obtaining the specimens and Drs. R.C. Turner and S. H. Ashcroft for helpful advice in the preparation of this manuscript. We are grateful to Drs. M.Appel, R. Chance and $J$. Ensinck for gifts of antibodies to glucagon, pancreatic peptide and somatostatin, respectively; and to Novo Industries and the Charles Wolfson Charitable Trust for grants. AG was supported by the Oxford Regional Health Authority Research Fund.

\section{References}

1. Like AA, Orci L (1972) Embryogenesis of the human pancreatic islets: A light and electron microscopic study. Diabetes 21: (Suppl 2) 511-534

2. Falin LI (1967) The development and cytodifferentiation of the is- 
lets of Langerhans in human embryos and foetuses. Acta Anat 68: 147-168

3. Pictet RL, Rall L, de Gasparo M, Rutter WJ (1975) Regulation of differentiation of endocrine cells during pancreatic development in vitro. In: Camerini-Davalos RA, Cole HS (eds) Early diabetes in early life. Academic Press, New York San Francisco London, pp 25-39

4. Malaisse-Lagae F, Stefan Y, Cox J, Perrelet A, Orci L (1979) Identification of a lobe in the adult human pancreas rich in pancreatic polypeptide. Diabetologia 17:361-365

5. Rahier J, Wallon J, Henquin J-C (1981) Cell populations in the endocrine pancreas of human neonates and infants. Diabetologia 20: $540-546$

6. Larsson L-I, Sundler F, Håkanson R (1975) Immunohistochemical localization of human pancreatic polypeptide (HPP) to a population of islet cells. Cell Tiss Res 156: 167-171

7. Orci L, Stefan Y, Malaisse-Lagae F, Perrelet A (1979) Instability of pancreatic endocrine cell populations throughout life. Lancet 1 : 615-616

8. Aynsley-Green A, Polak JM, Bloom SR, Gough MH, Keeling J, Ashcroft SJH, Turner RC, Baum JD (1981) Nesidioblastosis of the pancreas: definition of the syndrome and the management of the severe neonatal hyperinsulinaemic hypoglycaemia. Arch Dis Childhood 56: 496-508

9. Bishop AE, Polak JM, Garin Chesa P, Timson CM, Bryant MG, Bloom SR (1981) Decrease of pancreatic somatostatin in neonatal nesidioblastosis. Diabetes 30: 122-126

10. Streeter GL (1921) Weight, sitting height, head size, foot length and menstrual age of the human embryo. Contrib Embryol Carnegie Inst, Washington 55: 143-170

11. Nakane PK, Pierce GB (1967) Enzyme-labelled antibodies for the light and electron microscopic localization of tissue antigens. $\mathrm{J}$ Cell Biol 33: 307-318

12. Paulin C, Dubois PM (1978) Immunohistochemical identification and localization of pancreatic polypeptide cells in the pancreas and gastrointestinal tract of the human fetus and adult man. Cell Tiss Res 188: 251-257

13. Dubois PM, Paulin C, Assan R, Dubois MP (1975) Evidence for immunoreactive somatostatin in the endocrine cells of human foetal pancreas. Nature 256: 731-732

14. Orci L, Baetens D, Ravazzola M, Stefan Y, Malaisse-Lagae F (1976) Ilots à polypeptide pancreatique (PP) et îlots à glucagon: Distribution topographique distincte dans le pancréas de rat. C R Acad Sci (D) (Paris) 283: 1213-1216

15. Larsson L-I, Sundler F, Håkanson R (1976) Pancreatic polypeptide. A postulated new hormone: identification of its cellular storage site by light and electron microscopic immunocytochemistry. Diabetologia 12: 211-226

16. Rahier J, Wallon J, Henquin JC (1980) Abundance of somatostatin cells in the human neonatal pancreas. Diabetologia 18:251-254

17. Milner RDG, Wirdnam PK, Tsanakas J (1981) Quantitative morphology of B, A, D and PP cells in infants of diabetic mothers. Diabetes 30: 271-274

18. Pearse AGE (1969) The cytochemistry and ultrastructure of polypeptide hormone-producing cells of the APUD series and the embryologic, physiologic and pathologic implications of the concept. J Histochem Cytochem 17: 303-313

19. Koerker DJ, Ruch W, Chideckel E, Palmer J, Goodner CJ, Ensinck J, Gale CC (1974) Somatostatin: hypothalamic inhibitor of the endocrine pancreas. Science 184: $482-484$

Received: 22 October 1982

and in revised form: 27 March 1983

Dr. A Clark

Diabetes Research Laboratories,

Nuffield Department of Clinical Medicine,

Radcliffe Infirmary,

Woodstock Road,

Oxford OX2 6HE, UK 